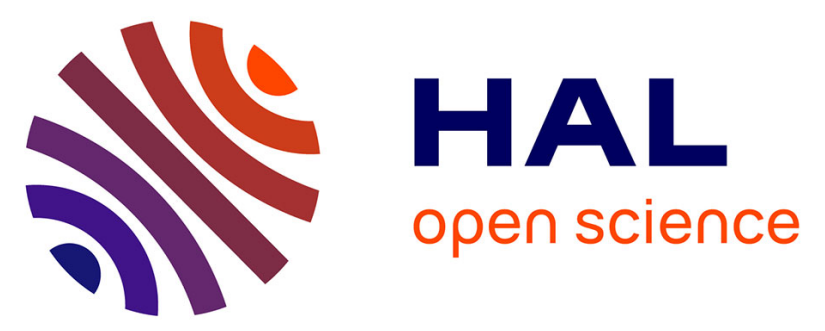

\title{
Influence of leaching on the local mechanical properties of an aggregate-cement paste composite
}

Mouad Jebli, Frédéric Jamin, Eric Garcia-Diaz, Mohamed El Omari, Moulay Saïd El Youssoufi

\section{- To cite this version:}

Mouad Jebli, Frédéric Jamin, Eric Garcia-Diaz, Mohamed El Omari, Moulay Saïd El Youssoufi. Influence of leaching on the local mechanical properties of an aggregate-cement paste composite. Cement and Concrete Composites, 2016, 73, pp.241 - 250. 10.1016/j.cemconcomp.2016.05.001 . hal-01405475

\section{HAL Id: hal-01405475 \\ https://hal.science/hal-01405475}

Submitted on 30 Nov 2016

HAL is a multi-disciplinary open access archive for the deposit and dissemination of scientific research documents, whether they are published or not. The documents may come from teaching and research institutions in France or abroad, or from public or private research centers.
L'archive ouverte pluridisciplinaire HAL, est destinée au dépôt et à la diffusion de documents scientifiques de niveau recherche, publiés ou non, émanant des établissements d'enseignement et de recherche français ou étrangers, des laboratoires publics ou privés. 


\title{
Influence of leaching on the local mechanical properties of an aggregate-cement paste composite
}

\author{
M. Jebli a, b, c, d, *, F. Jamin ${ }^{\text {a, b }}{ }^{\text {, E. Garcia-Diaz }}{ }^{\text {d }}$, M. El Omari ${ }^{\text {c }}$, M.S. El Youssoufi ${ }^{\text {a, b }}$ \\ a LMGC, CNRS, Université de Montpellier, Cc 048, 163 rue Auguste Broussonnet, 34090, Montpellier, France \\ ${ }^{\mathrm{b}}$ Laboratoire de Micromécanique et d'Intégrité des Structures MIST, IRSN-CNRS-Université de Montpellier, France \\ ${ }^{\mathrm{c}}$ LAEPT, Faculté des Sciences Semlalia, Université Cadi Ayyad, B.P 2390, 40000, France \\ d C2MA, Ecole des Mines dAlès, 6 Avenue de Clavières, 30319, Alès Cedex, France
}

\begin{abstract}
A B S T R A C T
This paper presents an experimental study to characterize the mechanical behaviour, at the local scale, of sound and degraded concrete after leaching. An experimental protocol was developed to study the ef-fects of the calcium leaching mechanism at the interfacial transition zone (ITZ) on the mechanical properties of the cement-aggregate interface and bulk paste of model material. The process of lixiviation with deionised water occurs very slowly. The experimental study in the laboratory was accelerated by replacing the water with an ammonium nitrate solution. To quantify the development and kinetics of degradation at the cemented bond, the concrete leaching fronts were characterized at different levels of degradation using phenolphthalein and local mechanical tests (compression and tensile) and performed on samples consisting of two aggregates bound by cement paste. Tests were performed on sound samples at different hydration times and on chemically degraded samples. The results show the effect of leaching on the mechanical properties of the samples and making it possible to correlate the progress of leaching to the evolution of these locally considered properties. The experimental results show that there is an ITZ effect on the alteration of the mechanical properties due to leaching.
\end{abstract}

\author{
Keywords: \\ Concrete \\ Leaching \\ Cement-aggregates scale \\ Interfacial transition zone (ITZ) \\ Mechanical tests
}

\section{Introduction}

The chemical degradation of concrete by leaching is the result of the liquid attack of (water with a low $\mathrm{pH}$ compared with the pore fluid) leading to the dissolution of the cement paste hydrates [1]. This is particularly true when the hydrates contain calcium $\left(\mathrm{Ca}^{2+}\right)$ as the main chemical component of the cement paste. For this reason, simplified approaches avoid the need to consider all the elementary chemical mechanisms and focus on the evolution of calcium ion concentration in the liquid and solid phases. Cement degradation is produced by several dissolution fronts depending on the relative solubility of each hydrate. The portlandite $(\mathrm{CH})$ contained in cement paste is the first mineral to be completely dissolved, followed by the progressive decalcification of $(C-S-H)$ over time $[1,10,32]$. This degradation, which develops from the surface by the diffusion of products dissolved towards the outside, leads to a significant increase in porosity. This, in turn, accelerates the process of material transport and the dissolution of hydrates, leading to modification of the microstructure of concrete. The physicochemical and mechanical properties of the concrete are gradually altered with the evolution of the degradation rate, so a loss of stiffness and strength of the concrete are observed [28]. Most experimental studies of the leaching effect on the mechanical properties of cementitious materials are investigated for bulk materials $[20,24,34]$ and show that the strength of the samples is significantly reduced after dissolution of the hydrates. It is also noted that the change in microstructure increases the ductility of chemically degraded material. However, the effect of leaching on the interfacial transition zone remains little studied in the scientific literature despite the fact that the presence of aggregates should influence the leaching process and mechanical behaviour of leached concrete [29]. So it is of interest to conduct investigations at the local scale in order to provide a better understanding of the mechanical behaviour of leached concrete and to characterize the effect of leaching at the Interfacial Transition Zone (ITZ) on the mechanical concentration at this scale.

The Interfacial Transition Zone (ITZ) is considered an additional phase introduced by the presence of aggregates [27]. It is 
characterized by a higher porosity than the bulk paste and a high concentration of portlandite $[4,11,16,31,40]$ which increases calcium leaching. The work of Zheng and al. [39] and Winslow and al. [37] have also shown that ITZ provides a preferential path for the transport of water and ions. In order to characterize the lixiviation effect of the ITZ on mechanical properties, a series of experiments was carried out by Carde and François [9] on a cement paste and mortar, with or without silica fume, demonstrating the effect of the ITZ on the mechanical properties of concrete. A recent experimental study by Buzzi and al. [8] showed that a leached rockconcrete interface at fixed leaching depth presents a radical change of behaviour because of the local loss of mechanical strength.

The process of lixiviation with deionised water occurs very slowly [1]. It has been shown that for concrete with a water/cement ratio of 0.4 , a degradation depth of $4 \mathrm{~cm}$ would necessitate a leaching time about of 300 years and very few data are available in the literature about long term degradation of concrete by pure water [35]. In order to collect experimental data in a reasonable period of time, it is necessary to use an accelerated procedure. There are three methods to accelerate calcium leaching of cementitious materials: application of an electric field [17,33], using temperature [21] and using different chemical solutions to increase concentration gradients between the interstitial solution and the aggressive environment [13,32]. Ammonium nitrate $\left(\mathrm{NH}_{4} \mathrm{NO}_{3}\right)$ has been chosen by several authors as a representative aggressive solution for these accelerated experiments [3,10,19,25,26,30,34]. The principle of accelerated degradation with ammonium nitrate is the penetration of $\mathrm{NH}^{4+}$ and $\mathrm{NO}^{3-}$ ions stemming from the dissolution of ammonium nitrate (Eq. (1)), in the interstitial solution by diffusion. The $\mathrm{NH}^{4+}$ ion reacts with the $\mathrm{OH}^{-}$of the interstitial solution (Eq. (2)) and the $\mathrm{NO}^{3-}$ ion reacts with the calcium ions (Eq. (3)). This consumption of $\mathrm{Ca}^{2+}$ ions disturbs the chemical balance of the calcium between the liquid and solid phases, causing the dissolution of hydrates to free new calcium ions (Eq. (4)).

$\mathrm{NH}_{4} \mathrm{NO}_{3} \Leftrightarrow \mathrm{NH}_{4}^{+}+\mathrm{NO}_{3}^{-}$

$\mathrm{NH}_{4}^{+}+\mathrm{OH}^{-} \Leftrightarrow \mathrm{NH}_{4} \mathrm{OH} \Leftrightarrow \mathrm{NH}_{3}+\mathrm{H}_{2} \mathrm{O}$

$\mathrm{Ca}^{2+}+2 \mathrm{NO}_{3}^{-} \Leftrightarrow \mathrm{Ca}\left(\mathrm{NO}_{3}\right)^{2}$

$\mathrm{Ca}(\mathrm{OH})_{2} \Leftrightarrow \mathrm{Ca}^{2+}+2 \mathrm{OH}^{-}$

These accelerated degradation tests make sense when it comes to studying coupled processes: degradation-cracking [6,34], degradation-permeability $[15,38]$ or degradation-mechanical behaviour $[10,17,18,36]$. This paper presents the effect of degradation on mechanical behaviour.

The proposed study is a contribution to the experimental characterization of the impact of chemical degradation by leaching of cementitious materials on mechanical properties at the cement paste-aggregate interface and the cement bond. In this context, a preliminary study was carried out on sound samples to characterize the behaviour of concrete during the hydration process. Interactions on this scale were experimentally analysed through mechanical testing of compression and tensile by means of a specific device.

\subsection{Sample design and materials selected}

For this study, the specimens consisted of two spherical "calcite" aggregates, the calcareous aggregates having been chosen for their high adhesion with the cement paste [22]. The aggregates were of the same diameter $(8.3 \mathrm{~mm})$, and were bound by a cement paste (cement CEM II/B $32.5 \mathrm{~N}$ ) with a ratio water/cement of 0.5 with a circular cross section. Aitcin [2] found a reduction in the porosity and thickness of the interfacial transition zone in the HighPerformance Concrete (HPC). Generally, the thickness of the ITZ of the HPC is limited to $12 \mu \mathrm{m}$, whereas that of ordinary concretes is about $50 \mu \mathrm{m}$. The distance between two aggregates was fixed at $1.7 \mathrm{~mm}$, this being the average distance between two large grains observed in a concrete [12]. According to the definition of De Larrard [23], the distance between these two large adjacent aggregates separated by the cement paste is called the Maximum Paste Thickness (MPT). The MPT affects the compressive strength of concrete. When MPT decreases, the compressive strength increases. the interstitial space between aggregates mobilized by the ITZ also increase. Another explanation is crystal orientation of $\mathrm{C}-\mathrm{S}-\mathrm{H}$, more the MPT is lower, more the hydrates are oriented, what improve resistance to compressive [23].

The geometric configuration of the sample is presented in Fig. 1 and the "material" data in Table 1. Simplified form of aggregates is used. These were perfectly spherical and of the same size, as originally proposed by Bisschop and Van Mier [5] to study the effect of aggregates on drying shrinkage in cement-based composites and by Burlion and al. [7] to study microcracking in leached cementitious materials. Demoulding was carried out after $24 \mathrm{~h}$. The sample obtained had a diameter of $8 \mathrm{~mm}$ and a height of about $18 \mathrm{~mm}$ : This sample was regarded as representative. The samples were stored in water saturated with lime at $21^{\circ} \mathrm{C}$ to reduce the leaching with water and the effects of drying shrinkage.

The specific sample geometry selected allowed us to consider the concrete as a three-phase material: aggregates, cementitious matrix and ITZ (Fig. 2). This allowed us to follow the direct effect of leaching at the ITZ interface and also in the bulk paste. Two sets of samples were examined: the first was kept in water saturated with lime at $21{ }^{\circ} \mathrm{C}$ (control series) and the second was immersed in the aggressive ammonium nitrate solution (degraded series), after

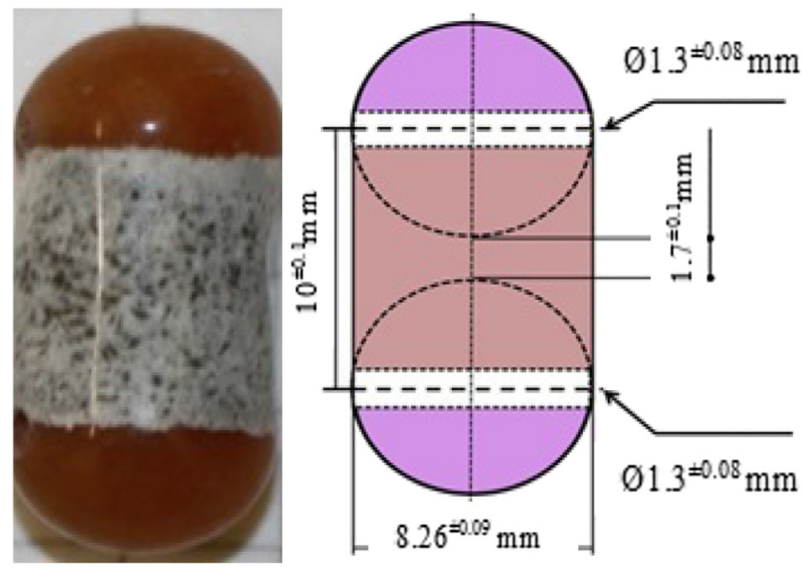

Fig. 1. Description of concrete samples at local scale.

Table 1

Material data of components used.

\begin{tabular}{ll}
\hline Aggregates & \\
Type & Calcite $\mathrm{CaCO}_{3}$ \\
Density & $2.6 \mathrm{~g} / \mathrm{cm}^{3}$ \\
Diameter & $8.26^{ \pm 0.09} \mathrm{~mm}$ \\
Cement paste & \\
Formula & $\mathrm{CEM} \mathrm{II/B-LL} \mathrm{32.5} \mathrm{N}$ \\
Water/Cement ratio & 0.5 \\
\hline
\end{tabular}




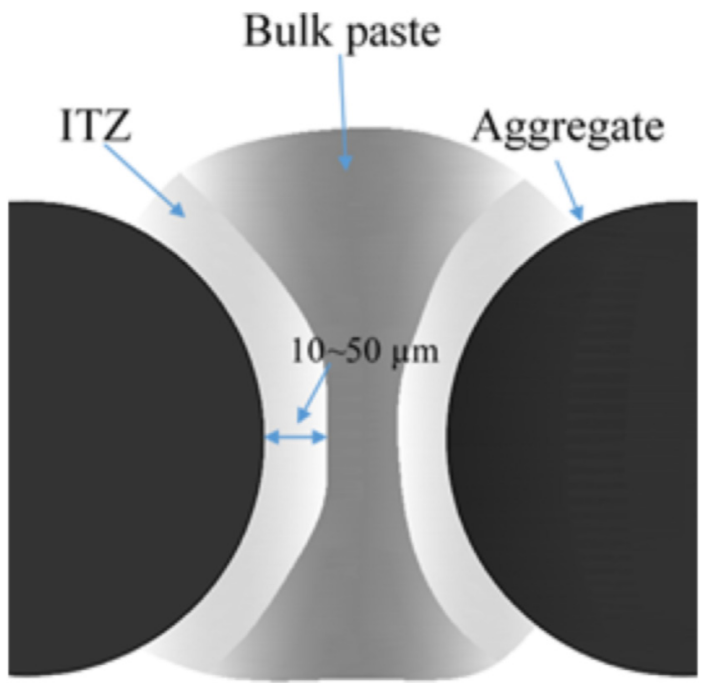

Fig. 2. Schematic diagram of the three-phase composite sphere for concrete.

being kept in water saturated with lime for 40 days.

After preparation, the samples were subjected to tensile or compressive tests at various times of hydration (from 1 to 40 days) to study the local behaviour of a cemented bond. The evolution of the mechanics of compression and tensile tests on samples was recorded with a high speed camera (Vision Research Phantom v12).

\subsection{Accelerated leaching process}

The objective of this experiment was to analyse the different states of chemical degradation of samples. This was achieved by an accelerated test able to replicate what is happening in reality to characterize the long-term behaviour of cement based materials. An accelerated test with ammonium nitrate solution was chosen.

After preparation, the samples were kept in water saturated with lime for the first 40 days and then immersed in a high volume of ammonium nitrate solution with a concentration of $6 \mathrm{~mol} /$ litre. The leaching process resulted from the high gradients of concentration between the pore solution in the cement paste and the aggressive solution surrounding the samples. The $\mathrm{pH}$ of the solution was monitored and the solution was renewed when the $\mathrm{pH} \geq 9.25$ [20]. The $\mathrm{pH}$ of the initial solution $\mathrm{NH}_{4} \mathrm{NO}_{3}$ concentrated to $480 \mathrm{~g} / \mathrm{l}$ was approximately equal to 6 . Once the sample was immersed in the solution, the $\mathrm{pH}$ quickly increased to $\mathrm{pH} 7$ then slowly increased and stabilized at $\mathrm{pH} 8$ (Fig. 3). Thereafter, at each time (respectively 1, 6, 24, 48, 72, 96 and $101 \mathrm{~h}$ ), the samples were extracted to measure the depth of chemical degradation and test their mechanical behaviour.

The degraded depth was determined using the phenolphthalein test on sectioned samples. The work presented by Le Bellégo [24] described the successful use of $\mathrm{pH}$ indicators to characterize the state of the chemical degradation of samples. Phenolphthalein changes colour when the $\mathrm{pH}$ is about 9 during the degradation of concrete, in the course of the alteration the $\mathrm{pH}$ varies from the initial value of the cement paste $(\mathrm{pH}=13)$ to that of ammonium nitrate solution $(\mathrm{pH}=6)$ characterising the acid environment. Therefore, phenolphthalein does not give the exact position of the dissolution front of portlandite. By comparing the measurement using $\mathrm{pH}$ indicators with that of SIMS microprobe analysis [24], has shown that for cement paste the total degraded depth $e_{t}$ can be corrected from the degraded thickness measured with phenolphthalein $e_{p h}$ by multiplying by a coefficient of 1.17 .

$e_{t}=1.17 \times e_{p h}$

\subsection{Mechanical tests}

Both the sound and degraded samples were subjected to compression and tensile tests at constant loading speed of $0.01 \mathrm{~mm} / \mathrm{s}$. The test monitoring in displacement seems better to get more information about the damage mechanisms involved. To measure their stiffness and force at rupture. All tests were performed on the same Mechanical Testing System (MTS) machine

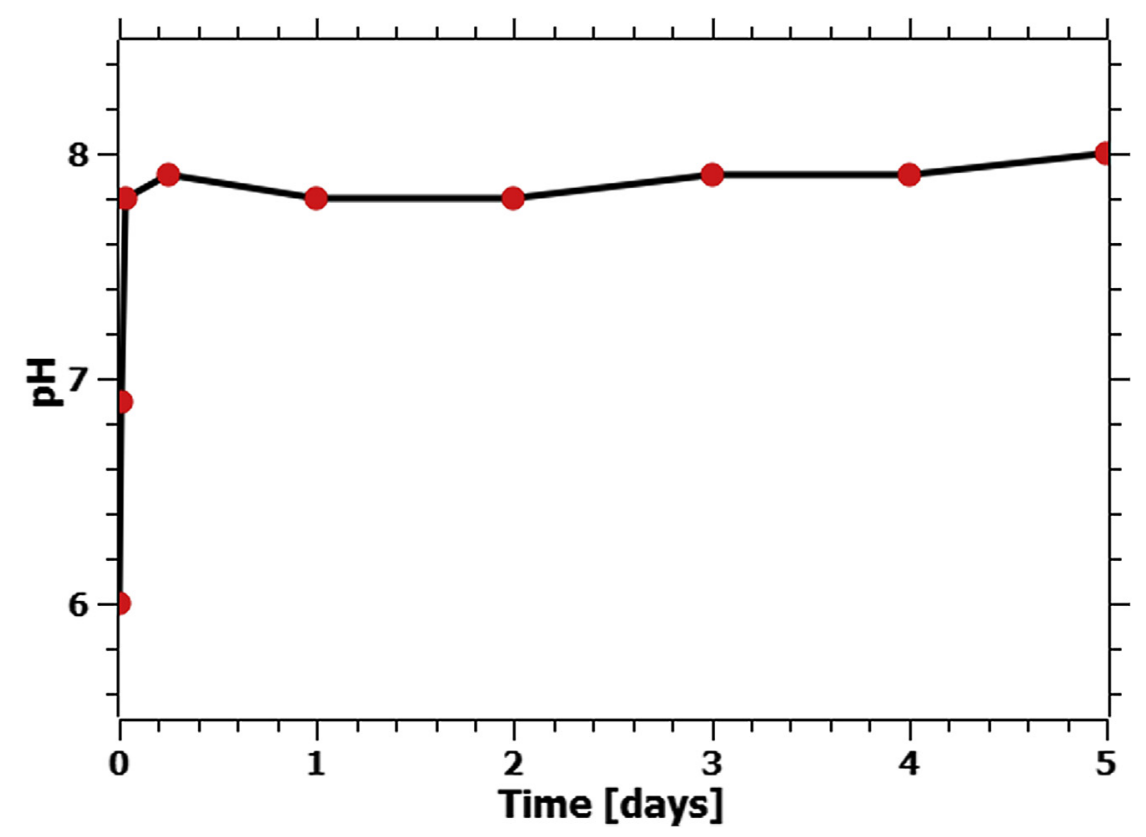

Fig. 3. Evolution of $\mathrm{pH}$ of the solution during the leaching test. 
equipped with a force sensor of $5000 \pm 10 \mathrm{~N}$ for compression tests and $500 \pm 1 \mathrm{~N}$ for tensile tests. The force applied to the sample and the longitudinal displacements were measured in the axial direction during the test.

To perform mechanical tests, specific accessories were produced, adapted to local testing. Fig. 4 shows the experimental device of the compression and tensile tests. Before each test, the dimensions and weight of each sample were measured. For each duration of hydration and degradation, four samples are subjected to compression or tensile mechanical testing.

\section{Results}

In this section, all the results obtained during mechanical testing are presented and discussed, for compression tests and tensile tests for sound samples and chemically degraded samples by leaching. A preliminary study was carried out on sound samples to characterize the behaviour of concrete during the hydration process at the local scale in the cement-aggregate interface and the cement paste bond. Interactions on this scale were analysed experimentally.

\subsection{Sound samples}

\subsubsection{Compression tests}

Mechanical tests were used to characterize the mechanical behaviour and fracture on the scale of the cement bond. The mechanical compressive test characterizes the mechanical properties of the cementitious binding. The maximum load was governed by the compressive strength of the bulk paste as shown in Fig. 5, where cracking develops along a generatrix in the cement bond.

Force - displacement curves during compression tests are

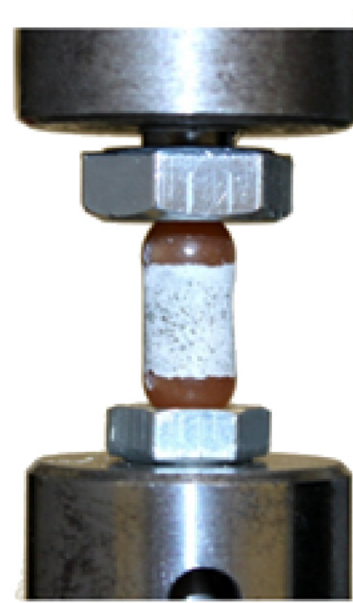

(a)

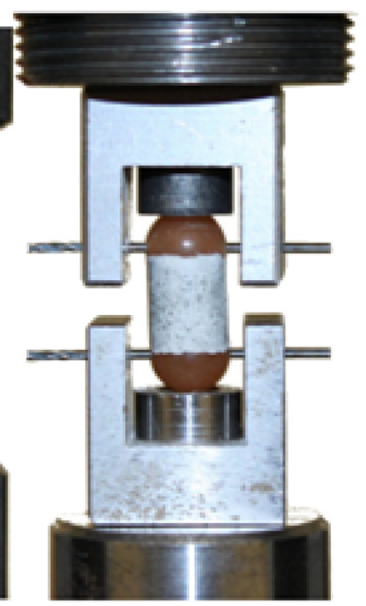

(b)
Fig. 4. Pictures of supports for (a) the compression test and (b) the tensile test.

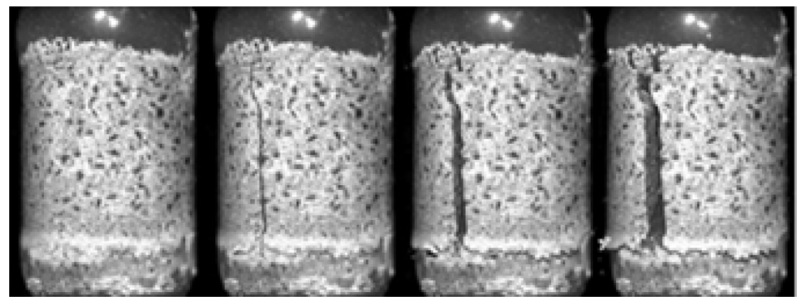

Fig. 5. Pictures of the sample during compression test (23 days of hydration). shown in Fig. 6 at different stages of hydration between 1 and 40 days.

These figures show a significant increase in the force at rupture and stiffness of the samples at the beginning of hydration, with almost constant values after more than three weeks of hydration. The examined samples in the compression test show ductile behaviour at a very early age, which become increasingly brittle. The values of the force at rupture noted $f(j)$ (in Newton) and stiffness $k(j)$, were estimated from the linear part of the slope of force-displacement curve calculated as shown in Fig. 7, depending on hydration time (in days); the compressiontest results are shown in Figs. 8 and 9. There was an increase of the forces at rupture and stiffness in compression during hydration with a drop in speed of evolution after 28 days.

The evolution of the force was approximated by an exponential function, based on the Eq. (6) presented in Eurocode 2 [14] to estimate the macroscopic resistance of concrete.

$f_{c}(j)=\beta_{c c} \times f_{c}(28)$

Where $f_{c}(28)=1500 \mathrm{~N}$ is the force at rupture in compression of the

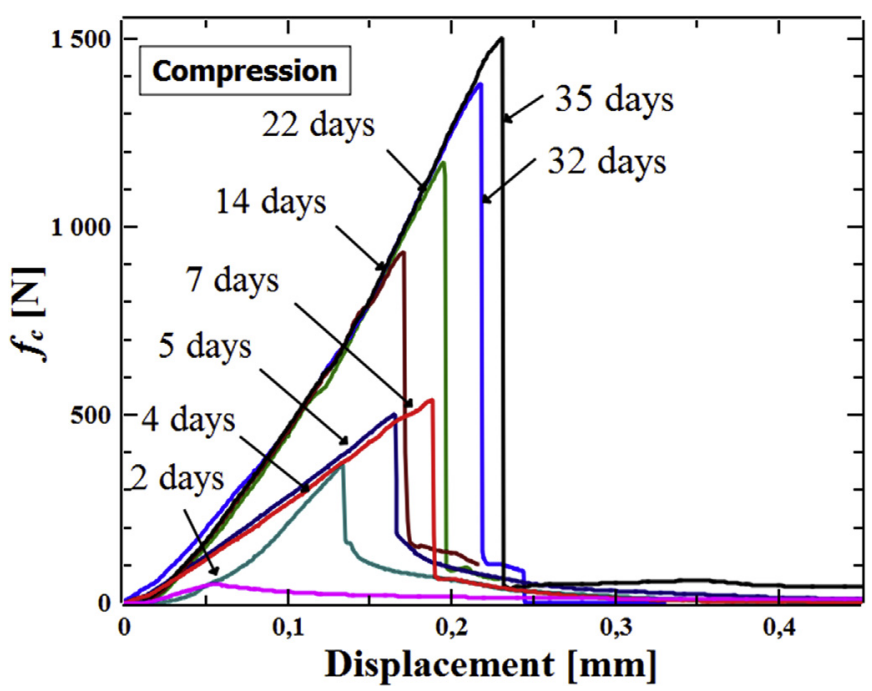

Fig. 6. Force - displacement Curves during compression tests.

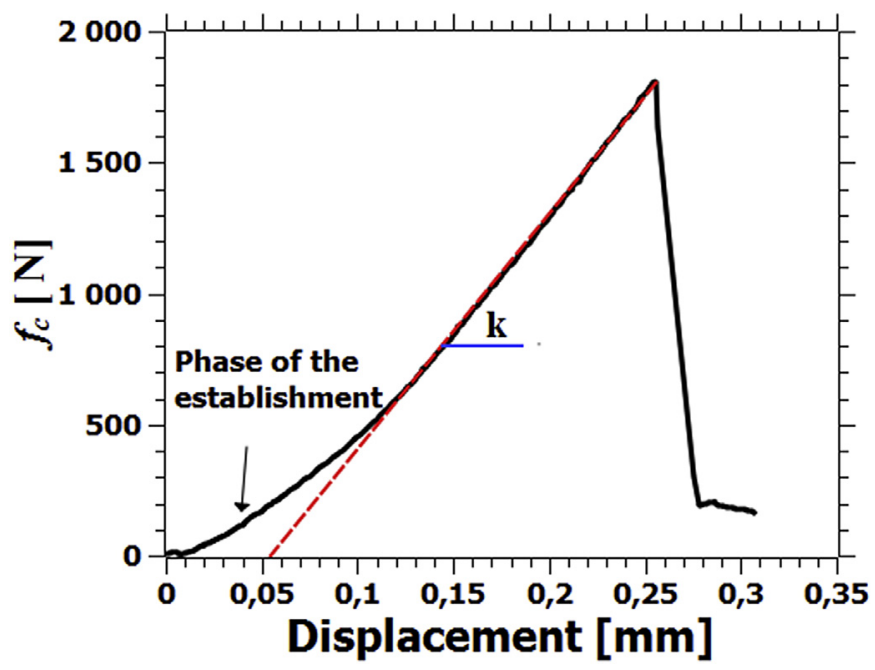

Fig. 7. Method of measuring stiffness. 


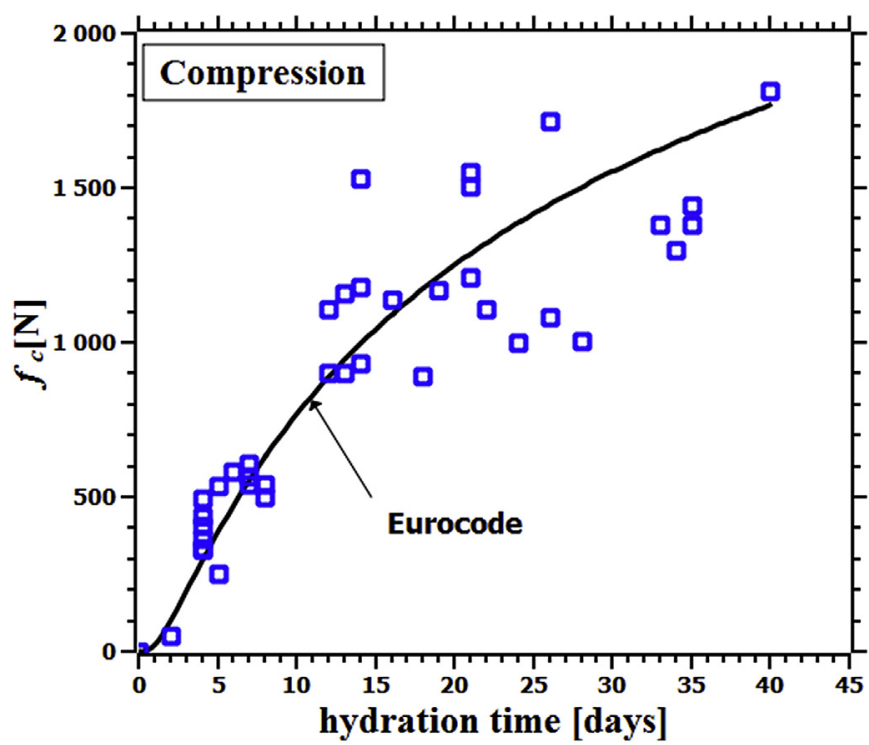

Fig. 8. Evolution of the force at rupture as a function of hydration time during mechanical tests.

samples at 28 days and $\beta_{c c}$ is a coefficient which depends on the age of the concrete according to the equation:

$\left.\beta_{c c}=\exp \left[s 1-\left(\frac{28}{j}\right)^{1 / 2}\right)\right]$

Where $s$ is a coefficient that depends on the type of cement, which is determined by linear interpolation. For the results obtained in this study $s=1$.

The stiffness $k(j)$ of the samples was estimated based on a slope of the linear part of the force-displacement curve. A similar exponential function (8) was used to approximate the evolution of the stiffness $k(j)$, based on the equation proposed in Eurocode 2 [14] in order to estimate the evolution of the elastic modulus with hydration time of concrete.

$k_{c}(j)=k_{c}(28) \times\left(\beta_{c c}\right)^{0.3}$

Where $k_{c}(28)=9 \mathrm{kN} / \mathrm{mm}$ is the stiffness at 28 days and the same $\beta_{c c}$ expression used before with $s=1$.

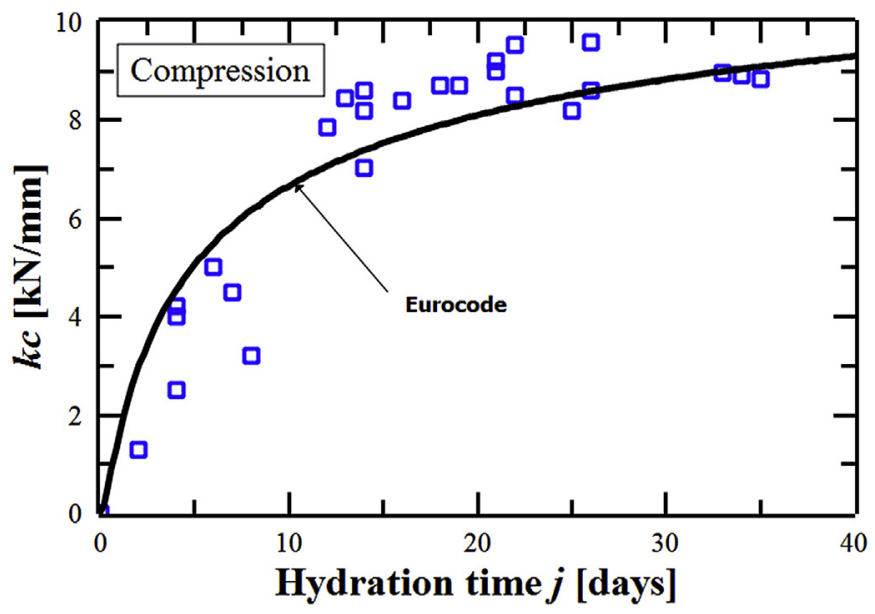

Fig. 9. Evolution of stiffness as a function of hydration time during mechanical tests.
The compression test characterizes the cement bond between two spherical aggregates, which is observed by the evolution of the crack all along the cement bond of the composite.

\subsubsection{Tensile tests}

The tensile force was derived from the maximum force recorded. Direct tensile testing is the most representative of this stress mode, but as it requires more preparation and carries a greater risk of failure, it is less used. The tensile tests in our study were used to characterize mechanical behaviour of the bulk paste and ITZ. While the cracking observed occurred only at the interface between aggregate and cement paste (weak area), no failure occurred in the cement paste bond or aggregate (Fig. 10).

The force - displacement curves during tensile tests were recorded as shown in Fig. 11 at different stages of hydration.

These figures show a significant increase in the force at rupture noted $f_{t}(j)$ (in Newton) at the beginning of hydration, which remained constant after more than three weeks of hydration. The values of the force at rupture noted $f_{t}(j)$ (in Newton), depending on hydration time (in days) of tensile tests are shown in Fig. 12.

The evolution of the force was approximated, like the compressive test, by an exponential function, based on the Eq. (9) presented in Eurocode 2 [14].

$f_{t}(j)=\left(\beta_{c c}\right)^{\alpha} \times f_{t}(28)$

Where $f_{t}(28)=150 \mathrm{~N}$ is the force at rupture in tensile of the samples at 28 days and $\beta_{c c}$ defined in Eq. (7). For the results obtained in this study, $\alpha=1$. It may also be noted that the value of suggested by Eurocode 2 [14] for values of $j \leq 28$ days is equal to 1 .

As at macroscopic scale, the composite samples at local scale showed very good compression behaviour and poorly resisted tensile testing. There was a ratio of ten between the forces at rupture of the compressive test $f_{c}(j)$ and the tensile test $f_{t}(j)$ which is generally accepted in the literature at the macroscopic scale. In the tensile test in our study the crack grew at the ITZ, so the tensile test characterizes ITZ behaviour is concluded.

\subsection{Altered samples}

\subsubsection{Chemical degradation tests: leaching}

Having put the phenolphthalein in the transverse and radial sample cross-section, two distinct zones could be observed: an area in pink (sound zone) and an area in grey (degraded zone). Illustrations are presented in Fig. 13 for different degradation times. On the sample surface, the thickness of degradation is measured. As we have seen, the degradation thickness was homogeneous. There was almost no dispersion, the results with very little dispersion of about $\pm 0.1 \mathrm{~mm}$ are obtained.

For each degradation duration, the sound surface $S_{S}$ is measured and the degraded surface $S_{d}=S_{0}-S_{s}$ is deduced, where $S_{0}$ is the initial surface. To follow the progress of the degradation process, we define a degradation rate $\delta$ corresponding to the ratio of the degraded surface by the initial surface:

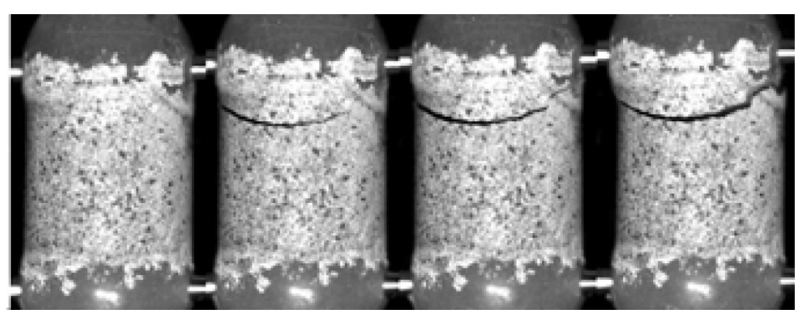

Fig. 10. Pictures of the sample during tensile test (21 days of hydration). 


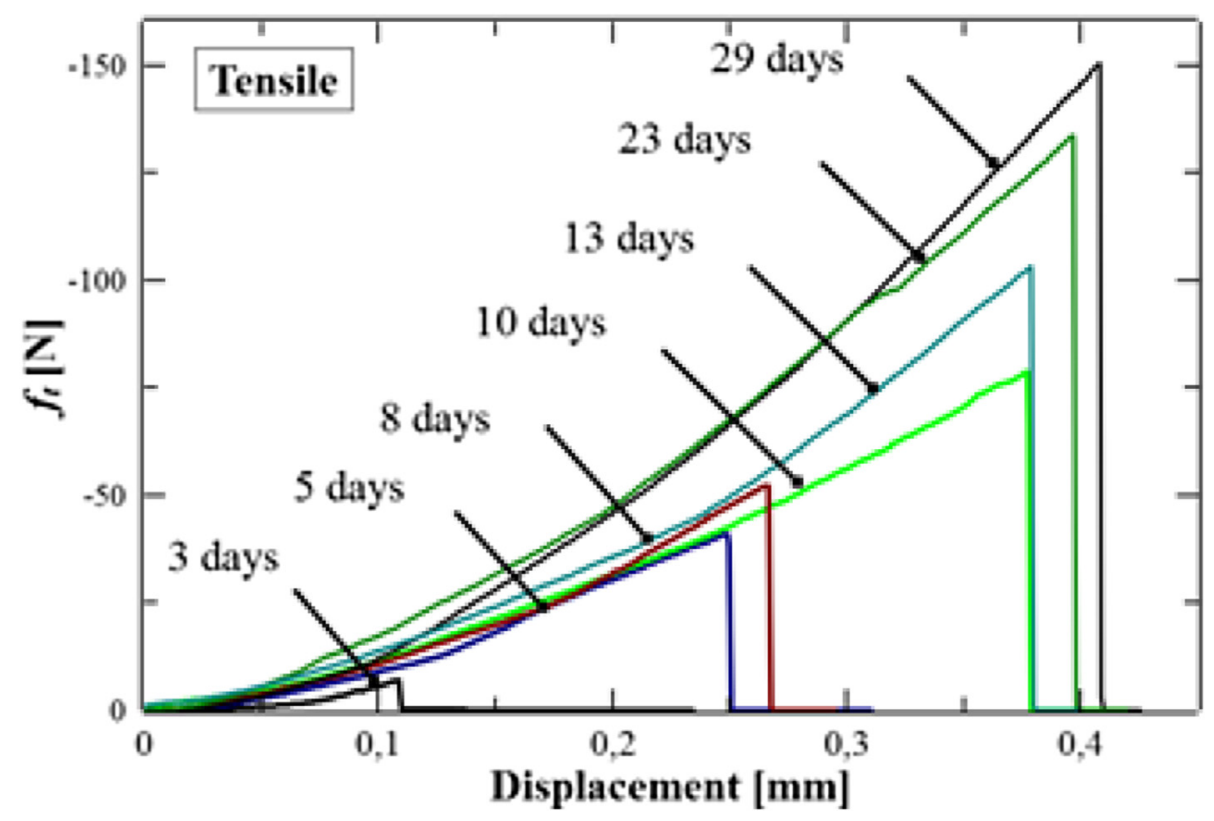

Fig. 11. Force - displacement Curves during tensile tests.

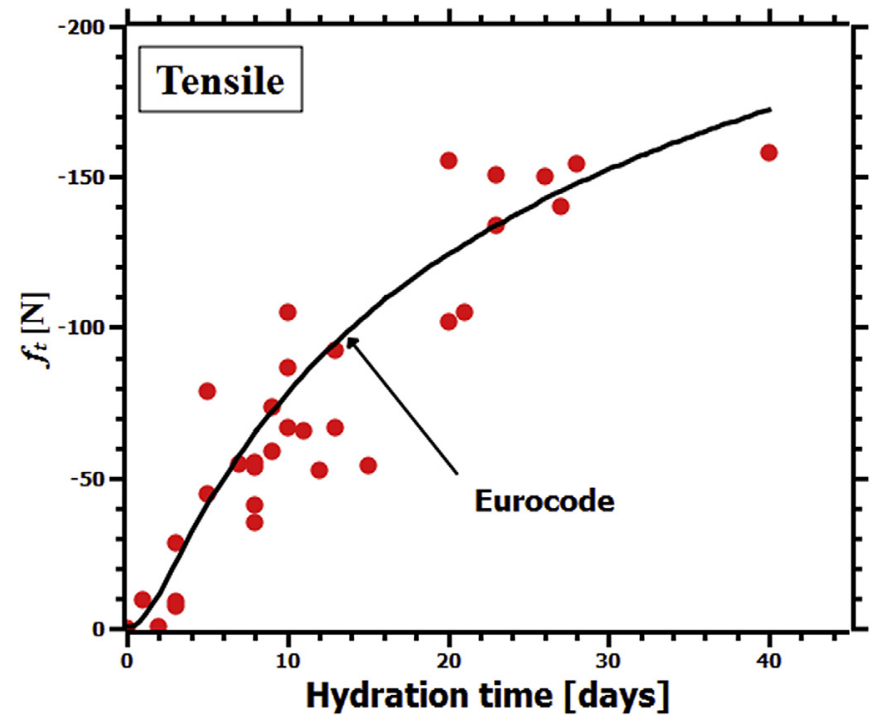

Fig. 12. Evolution of the force at rupture as a function of hydration time during mechanical tests.

$\delta=\frac{S_{d}}{S_{0}}=\frac{S_{0}-S_{S}}{S_{0}}$

Figs. 14 and 15 show the evolution of degraded thickness and mass loss as a function of degradation time ( $1 \mathrm{~h}, 6 \mathrm{~h}, 1$ days, 2 days and 3 days) and degraded rate $\delta$. Beyond 3 days, the samples are totally degraded.

Degradation is governed by a diffusion process and can be described by Fick's law relating degraded thickness to the square root of the time. Fig. 14 shows a linear evolution of the degraded thickness(e) measured in relation to the square root of immersion time in the aggressive solution with the formula:

$e=p \times \sqrt{t}$
Using the $p$ value, the other degradation time which be used for qualitative estimates can be predicted, depending on the cement type and characteristics of the acceleration method of degradation used.

The evolution of the degradation kinetics has been shown experimentally by other authors $[20,24,29,34]$ using the same method of accelerated degradation at the macroscopic scale. In our case, at the local scale, the value of the slope $p$ was equal to $2 \mathrm{~mm}$ by $\sqrt{\text { day. }}$

Chemical degradation of the concrete due to dissolution of the hydrates caused a loss mass in the samples. Fig. 15 shows the loss of mass in relation to the degraded rate $\delta$.

\subsubsection{Mechanical tests: compression and tensile tests}

At each time interval of chemical degradation, the concrete samples were subjected to compression and tensile tests to characterize the effect of leaching on the mechanical properties at different chemical degradation rates respectively for $6,24,48,72$, 96 and $101 \mathrm{~h}$. The case of the sound sample, taken as a reference, was stored in water saturated with lime for 40 days.

The evolution of the forces at rupture (for compression and tensile tests) is then represented according to rate $\delta$ (Eq. (10)) to highlight the effect of the degradation on forces. Considering these results, it is possible to define a critical degradation rate $\delta_{\text {crit }}$ (Figs. 17 and 20). This critical rate corresponds to the intersection of the linear segments at the beginning and at the end of the degradation curve (Figs. 17 and 20).

For the compression test: Figs. 16 and 17 show that at the start of chemical attack (for 1 and $6 \mathrm{~h}$ ) there was no effect on the compressive force at rupture. The decrease of stiffness and force at rupture of the samples began after the degraded rate $\delta$ has exceeded $\delta_{\text {crit }}$, as shown in Fig. 17, i.e. a significant dissolution of the cement paste to observe the decrease of the force at rupture. Also the behaviour of the degraded concrete became more and more ductile.

When the cement paste was completely leached, the force at rupture was about three times lower than the reference value. Similar results were obtained by Le Bellégo [24] and Nguyen [29]. The decrease in forces at rupture with the increasing of the 
(a) vertical section
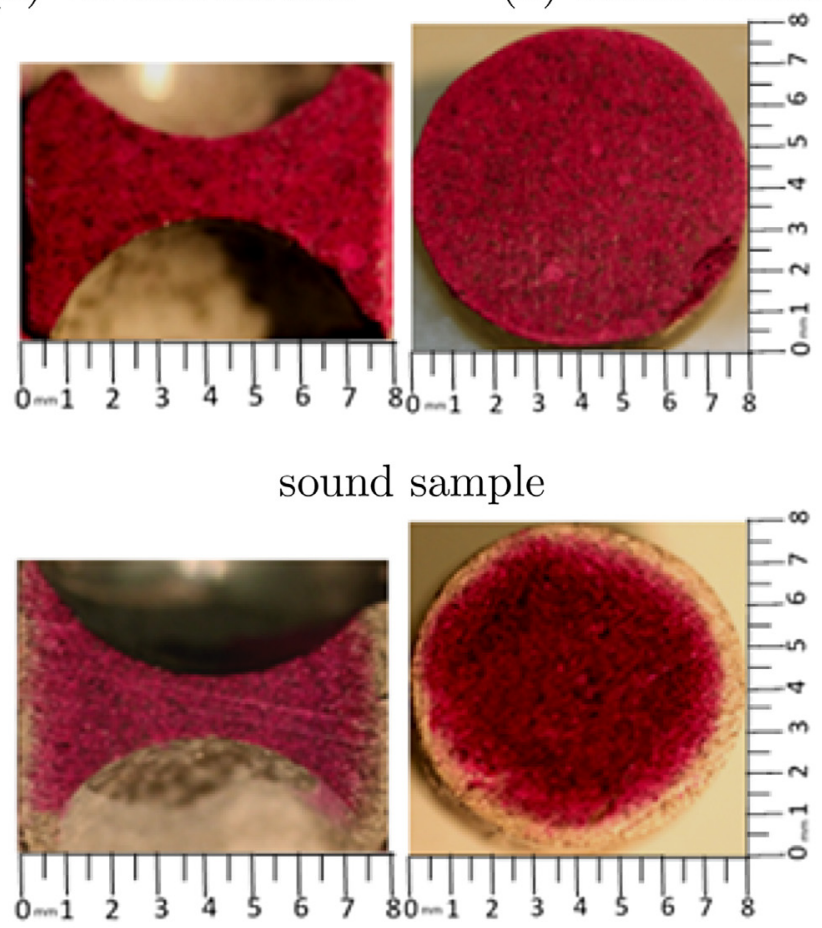

6 hours of degradation

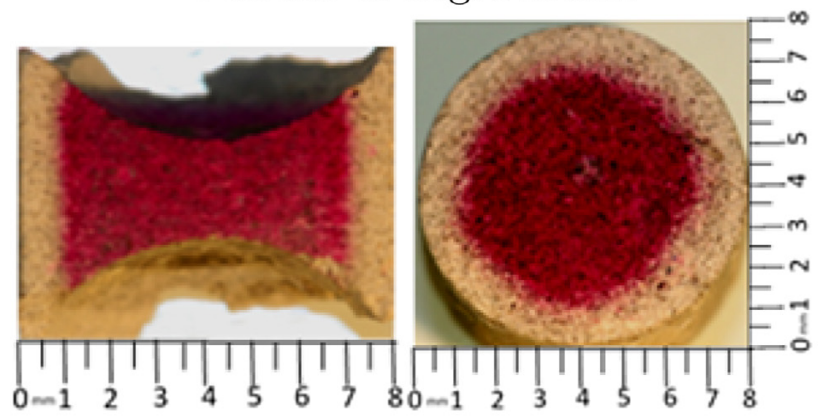

24 hours of degradation

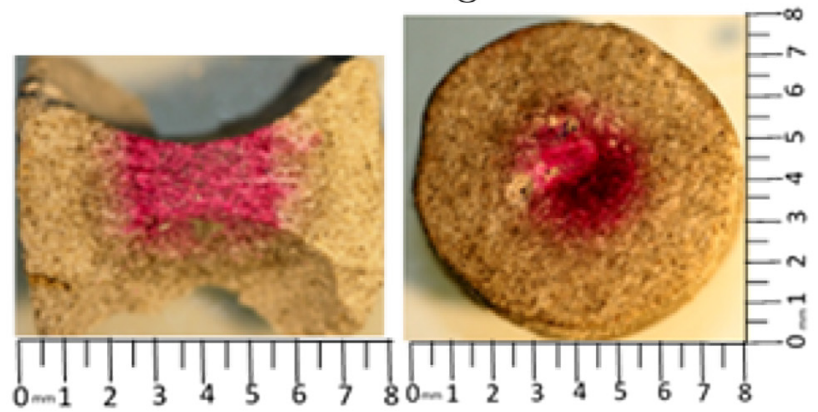

72 hours of degradation

Fig. 13. Measurement of degraded thickness using phenolphthalein, on samples having undergone respectively $0,6 \mathrm{~h}, 24 \mathrm{~h}, 72 \mathrm{~h}$ chemical degradation by $\mathrm{NH}_{4} \mathrm{NO}_{3}$. (a) transverse cross-section (b) radial cross-section.

degradation rate results from the increase of porosity of the degraded zone. This leads to the initiation of a cracks series in the damaged area as shown in Fig. 18. A strong impact coupling

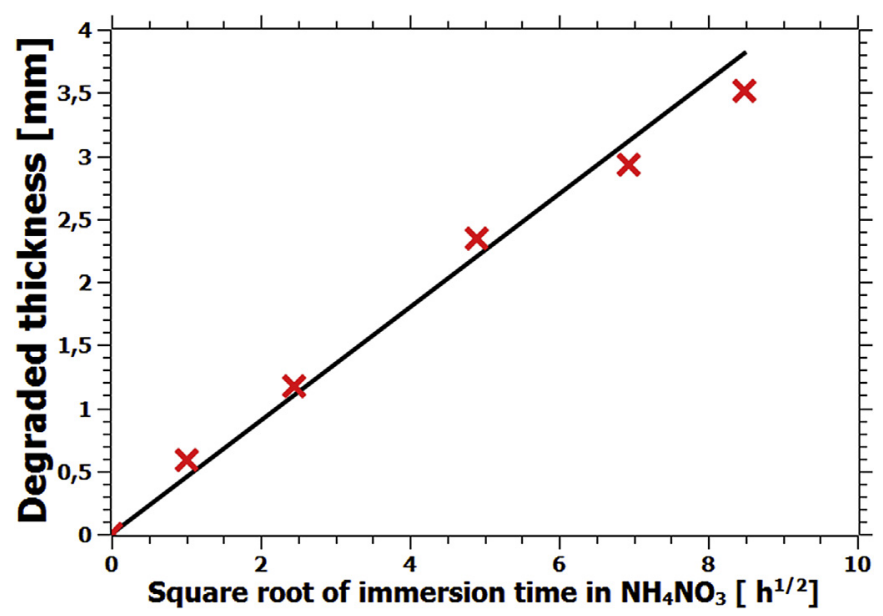

Fig. 14. Evolution of degraded thickness as a function of square root immersion time. $(\sqrt{\text { day }})$

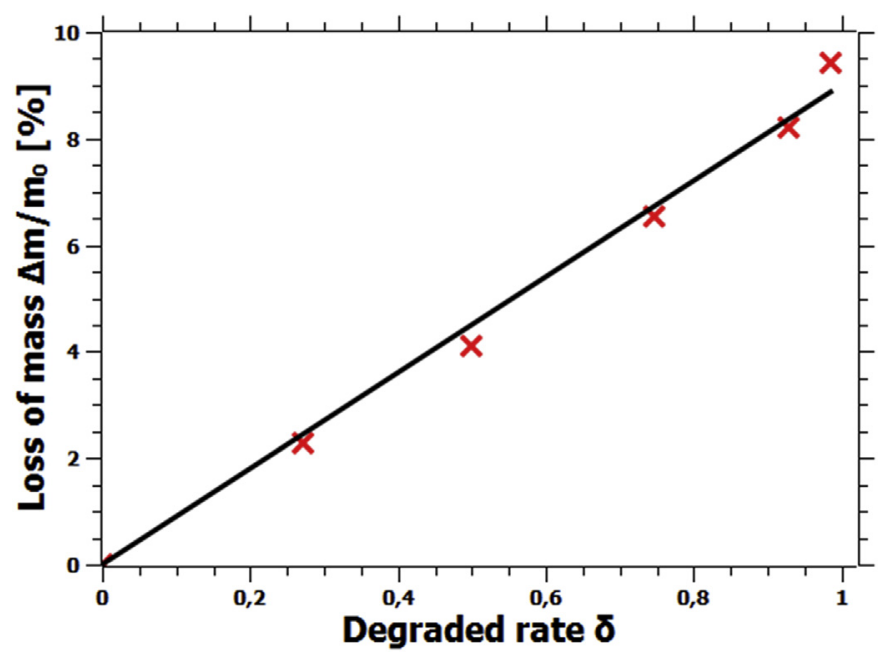

Fig. 15. Variation of the loss mass in relation to degraded rate.

between chemical degradation by leaching and the mechanical behaviour of the composite in compression is noted.

For the tensile test: very few tests have been performed on the effect of chemical degradation on the mechanical properties of concrete by direct tensile testing, due to the difficulty of realization, so we were unable to find results in the literature. Figs. 19 and 20 show the fast drop in tensile force at rupture and the stiffness of degraded samples by about $50 \%$ after just $1 \mathrm{~h}$ of degradation in the aggressive solution.

A strong impact of chemical degradation on mechanical behaviour is noted, more marked in the case of tensile soliciting the paste-aggregate interface. In the case of the compression test, the force at rupture $f_{c}$ is less affected when a degradation rate $\delta$ lower than $\delta_{\text {crit }}$. Beyond $\delta_{\text {crit }}$, the force at rupture drops suddenly. Indeed the sound transverse surface of the sample supports applied forces until a nearby degradation rate of $\delta_{\text {crit }}$ (Fig. 17). However, in the case of the tensile test, the force at rupture $f_{t}$ is affected for low values of $\delta$ (Fig. 20). This result, shown experimentally in this study can be correlated to the theoretical results, showing that the degradation kinetics of ITZ are accelerated, due to the higher porosity and concentration of portlandite at the interface. Indeed, these two factors work to accelerate the leaching process and the transport of 


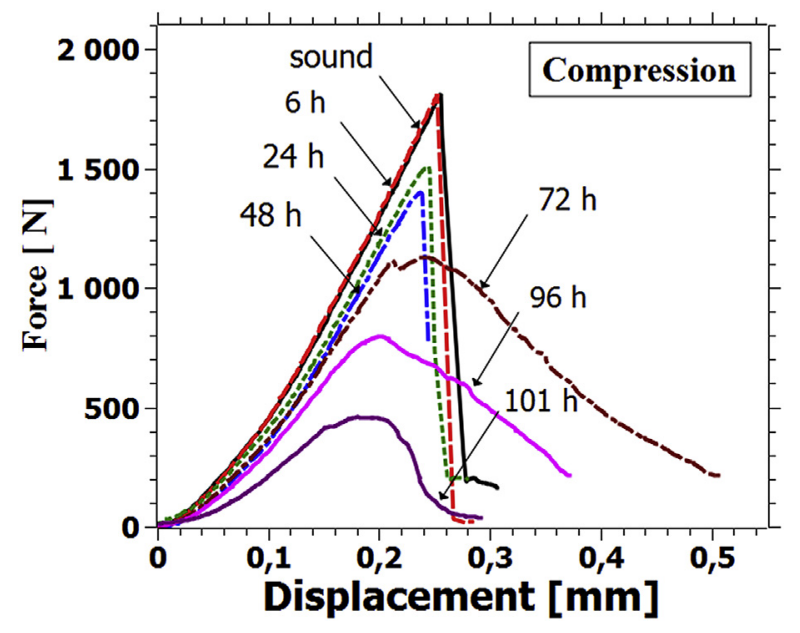

Fig. 16. Mechanical behaviour of sound and partially degraded samples under compression tests.

material, leading to the loss of cohesion between the bulk paste and aggregates as shown in Fig. 21. This results could not be observed with phenolphthalein du to the weak thickness of ITZ.

\section{Discussion}

The chemical attack by leaching induces the total dissolution of the calcium hydroxide and progressive decalcification of $\mathrm{CSH}$, leading to an increase in porosity and a decrease of mechanical properties. Most experimental studies on the effect of the cementitious material leaching on mechanical properties are carried out on a macroscopic and mesoscopic scale. So it was of interest to perform experiments at the local scale to understand the degradation mechanism on this scale. As shown above, all the rupture

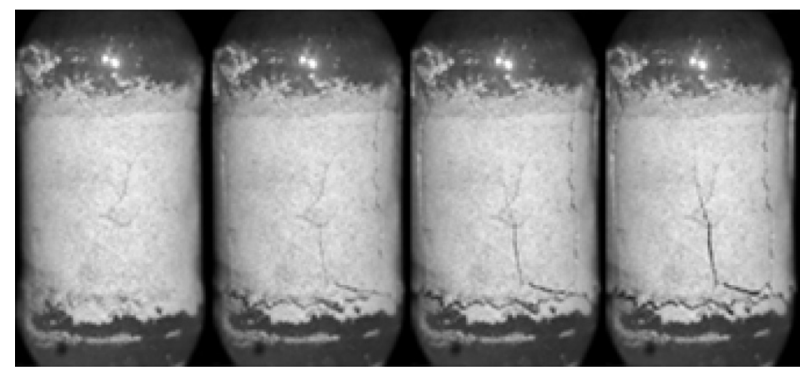

Fig. 18. Pictures of crack evolution of degraded sample during compression test after $72 \mathrm{~h}$ of degradation.

facies in the case of tensile tests show that cohesion loss occurs at the cement paste-aggregate interface. Besides, the degradation of the tensile strength properties occurs for relatively low degradation rate. This suggests that the interface properties are more sensitive to the degradation than those of the bulk paste. It is well known that the porosity of the ITZ is always greater than the porosity in the bulk paste. So, the chemical attack front, controlled by the diffusion of the ions, is naturally accelerated at the interface, more porous and thus more permeable.

Fig. 22 illustrates this statement. It shows how the degradation of the interface could be much faster than the degradation of the bulk paste, and how it could be widely underestimated by the overall degradation rate.

The mechanical compression test showed the effect of leaching in the cemented bond between the two aggregates. There was a drop in force at rupture and there were changes in behaviour with the increase of leaching, as is observed at macroscopic scale. This is explained by the increase in porosity due to dissolution of the hydrates. The chemical alteration of the interface did not affect the results of the compression test.

The tensile test directly characterized the ITZ in our chosen

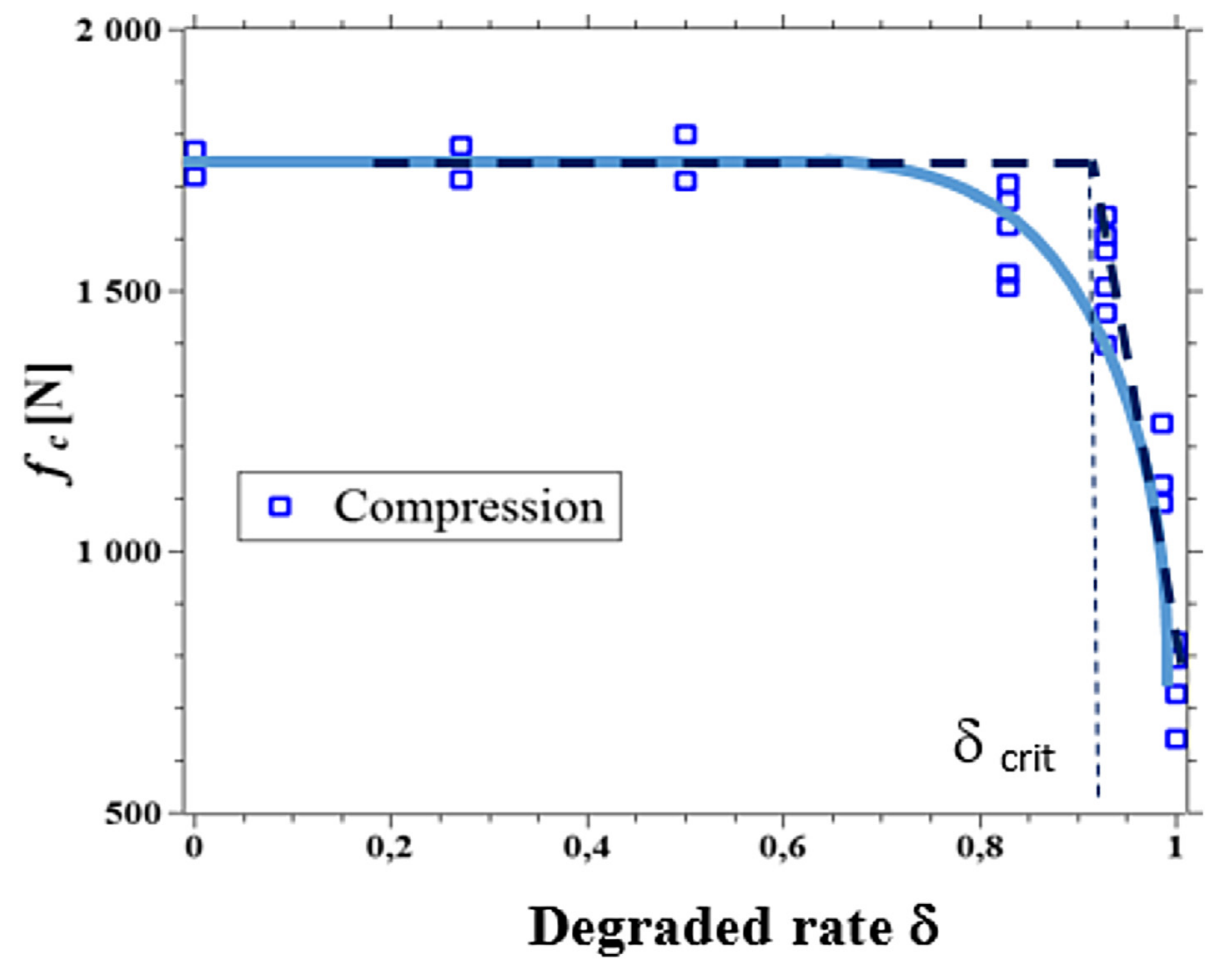

Fig. 17. Evolution of the force at rupture as a function of degraded rate during mechanical tests. 


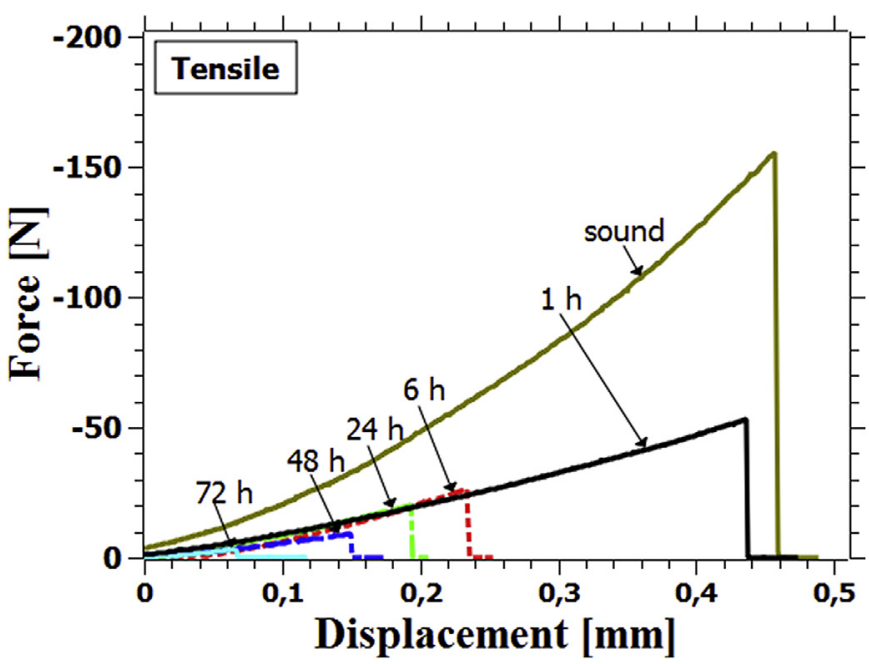

Fig. 19. Mechanical behaviour of sound and partially degraded samples under tensile tests.

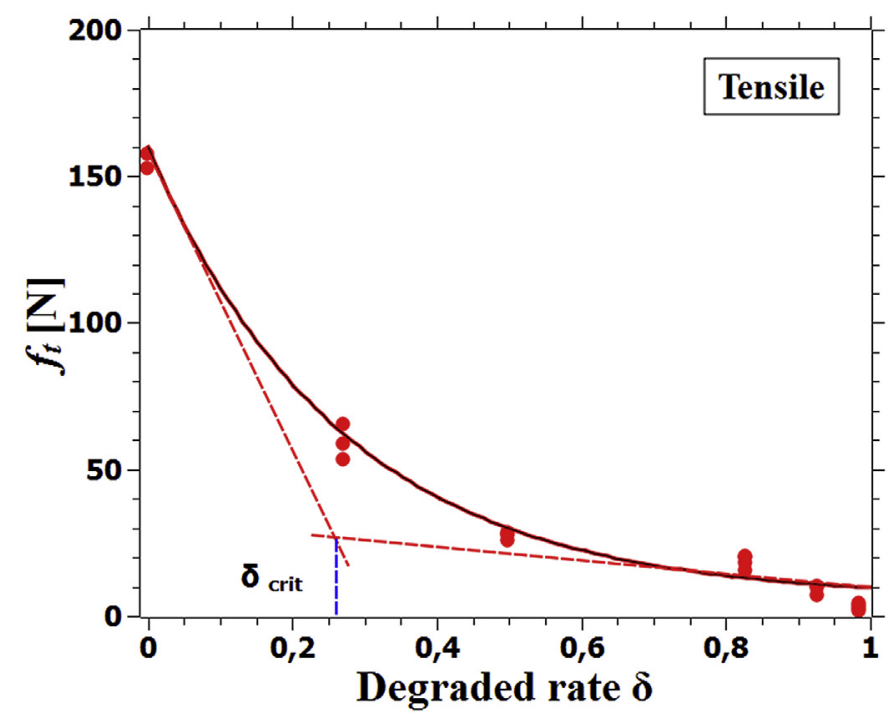

Fig. 20. Evolution of the force at rupture as a function of degraded rate during mechanical tests.

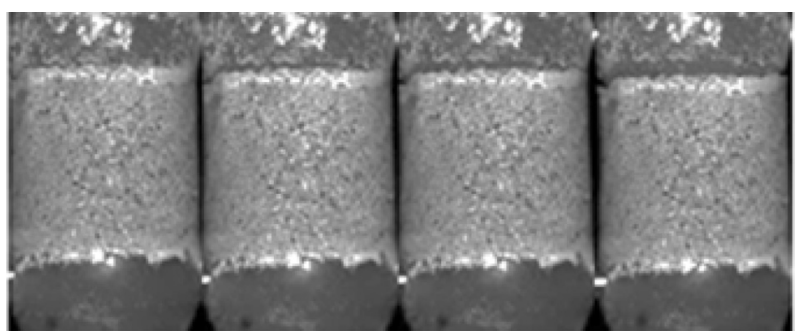

Fig. 21. Pictures of crack evolution of degraded sample during tensile test after $72 \mathrm{~h}$ of degradation.

geometry of samples. Very interesting results are obtained in terms of the kinetics of ITZ degradation. There was a very fast decrease of tensile force at rupture after just one hour of degradation. This was not the case in the compression test. This can be explained by the higher degradation kinetics of ITZ, resulting from the loss of
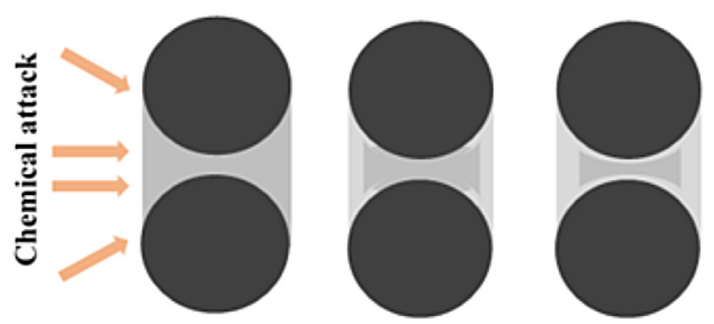

Fig. 22. Diagram of the degradation evolution of the composite at the ITZ and the bulk paste.

cohesion between the cement paste and aggregate, and a significant decrease in the mechanical properties of this zone.

\section{Conclusion}

An original experimental programme of the chemical mechanical behaviour of leached concrete at cement-aggregate interface scale is presented. Leaching at this scale clearly showed the important role of the paste-aggregates interface in the concrete leaching process. Mechanical compressive tests showed the chemo-mechanical behaviour of leached concrete, and a strong coupling between calcium leaching and mechanical behaviour is noted. As the duration of leaching increased, a loss of stiffness and force at rupture was observed: the mechanical behaviour was modified by leaching, and it became more ductile as leaching increased. The tensile test showed the effect of ITZ degradation by calcium leaching on the change in mechanical properties. The kinetics of chemical degradation by leaching were greater for the ITZ than for other areas, as seen by the abrupt loss of tensile strength after just a few hours of immersion in the aggressive solution $\left(\mathrm{NH}_{4} \mathrm{NO}_{3}\right)$. More research needs to be performed to fully analyse these experimental results. Modelling on this scale with appropriate numerical tools should allow investigations at the Representative Elementary Volume scale and identification of the behaviour laws, in the context of the durability and aging of concrete issue.

\section{References}

[1] F. Adenot, Durabilité du béton: caractérisation et modélisation des processus physiques et chimiques de dégradation du ciment, 1992 (Ph.D. thesis, France).

[2] P. Aitcin, The durability characteristics of high performance concrete: a review, Cem. Concr. Compos. 25 (2003) 409-420.

[3] A. Bajza, I. Rousekeva, O. Vrana, Corrosion of hardened cement paste by ammonium nitrate, in: 8th International Congress of the Chemistry of Cement, vol. 5, 1986, pp. 99-103.

[4] D. Bentz, E. Garboczi, Guide to Using HYDRA3D: a Three-dimensional Digitalimage-based Cement Microstructural Model, Technical Report, National Institute of Standards and Technology, Gauthersburg, MD, 1992.

[5] J. Bisschop, J. Van Mier, Effect of aggregates on drying shrinkage microcracking in cement-based composites, Mater. Struct. 35 (2002) 453-461.

[6] N. Burlion, D. Bernard, D. Chen, X-ray microtomography: application to microstructure analysis of a cementitious material during leaching process, Cem. Concr. Res. 36 (2006) 346-357.

[7] N. Burlion, T. Rougelot, D. Bernard, Les apports de la microtomographie et fissuration: cas d'un composite ciment-verre en cours de lixiviation, in: 18ème Congrès Français de Mécanique (Grenoble 2007), 2007.

[8] O. Buzzi, M. Boulon, M. Hervé, K. Su, Leaching of rock-concrete interfaces, Rock Mech. Rock Eng. 41 (2008) 445-466.

[9] C. Carde, R. François, Effect of the leaching of calcium hydroxide from cement paste on mechanical and physical properties, Cem. Concr. Res. 27 (1997) 539-550.

[10] C. Carde, R. Francois, J. Torrenti, Leaching of both calcium hydroxide and csh from cement paste: modeling the mechanical behavior, Cem. Concr. Res. 26 (1996) 1257-1268.

[11] S. Caré, Influence of aggregates on chloride diffusion coefficient into mortar, Cem. Concr. Res. 33 (2003) 1021-1028.

[12] F. De Larrard, Concrete mixture Proportioning: a Scientific Approach, CRC Press, 1999. 
[13] A. Delagrave, Mechanisms of Chloride Ion Penetration of Normal and High Performance Cement Based Systems, Ph.D. thesis, Université de Laval, Canada, 1996.

[14] B. EN, 1-1: 2004 Eurocode 2: Design of Concrete Structures, 1992.

[15] C. Gallé, V. LHostis, H. Peycelon, M. Helie, A. Millard, P. Lachaize, Durabilité du béton des infrastructures et des colis pour le stockage graphite, 2004. Rapport Technique RTDPC. Technical Report SCMME/04-672-A, CEA.

[16] E. Garboczi, L. Schwartz, D. Bentz, Modeling the influence of the interfacial zone on the dc electrical conductivity of mortar, Adv. Cem. Based Mater. 2 (1995) 169-181.

[17] B. Gérard, O. Didry, J. Marchand, D. Breysse, H. Hornain, Modelling the Longterm Durability of Concrete Barriers for Radioactive Waste Disposals, Technical Report, Electricité de France (EDF), Direction des Etudes et Recherches, Paris, France, 1996

[18] E. Guillon, F. Benboudjema, M. Moranville, Modelling the mechanical evolution of a chemically degraded cement paste at the microstructure scale, in: FRAMCOS, vol. 5, 2004, pp. 12-16.

[19] F. Heukamp, Chemomechanics of Calcium Leaching of Cement-based Materials at Different Scales: the Role of $\mathrm{CH}$-dissolution and CSH Degradation on Strength and Durability Performance of Materials and Structures, Ph.D. thesis, Massachusetts Institute of Technology, 2003.

[20] F. Heukamp, F.-J. Ulm, J. Germaine, Mechanical properties of calcium-leached cement pastes: triaxial stress states and the influence of the pore pressures, Cem. Concr. Res. 31 (2001) 767-774.

[21] S. Kamali, B. Gérard, M. Moranville, Modelling the leaching kinetics of cementbased materials influence of materials and environment, Cem. Concr. Compos. 25 (2003) 451-458.

[22] S. Kamali-Bernard, D. Keinde, F. Bernard, Effect of aggregate type on the concrete matrix/aggregates interface and its influence on the overall mechanical behavior. A numerical study, in: Key Engineering Materials, vol. 617, 2014, pp. 14-17. Trans Tech Publ.

[23] F. de Larrard, A. Belloc, The influence of aggregate on the compressive strength of normal and high-strength concrete, ACI Mater. J. 94 (1997).

[24] C. Le Bellégo, Couplage chimie mécanique dans les structures en béton armé attaquées par l'eau-Etude expérimentale et analyse numérique, Ph.D. thesis, ENS de Cachan, France, 2001.

[25] C. Le Bellégo, B. Gérard, G. Pijaudier-Cabot, Chemo-mechanical effects in mortar beams subjected to water hydrolysis, J. Eng. Mech. 126 (2000)
$266-272$.

[26] F. Lea, The action of ammonium salts on concrete, Mag. Concr. Res. 17 (1965) $115-116$.

[27] J. Maso, La liaison entre les granulats et la pâte de ciment hydraté, in: 7ème Congrès International de la chimie des ciments, Rapport principal, 1980.

[28] P. Mason, The effects of aggressive water on dam concrete, Constr. Build Mater. 4 (1990) 115-118.

[29] V. Nguyen, Couplage dégradation chimique-comportement en compression du béton, Ecole des Ponts ParisTech, France, 2005. Ph.D. thesis.

[30] V. Nguyen, B. Nedjar, J. Torrenti, Chemo-mechanical coupling behaviour of leached concrete: part ii: modelling, Nucl. Eng. Des. 237 (2007) 2090-2097.

[31] J. Ollivier, J. Maso, B. Bourdette, Interfacial transition zone in concrete, Adv. Cem. Based Mater. 2 (1995) 30-38.

[32] E. Revertegat, C. Richet, P. Gegout, Effect of ph on the durability of cement pastes, Cem. Concr. Res. 22 (1992) 259-272.

[33] H. Saito, S. Nakane, S. Ikari, A. Fujiwara, Preliminary experimental study on the deterioration of cementitious materials by an acceleration method, Nucl. Eng. Des. 138 (1992) 151-155.

[34] C. Tognazzi, Influences couplées de la fissuration et de la dégradation sur transferts dans les betons, in: Congrès Universitaire de Génie Civil: Concours Jeunes Chercheurs, 1998.

[35] J. Trägårdh, B. Lagerblad, Leaching of 90-year Old Concrete Mortar in Contact with Stagnant Water, Technical Report, Swedish Nuclear Fuel and Waste Management Co., Stockholm (Sweden), 1998.

[36] F. Ulm, J. Torrenti, F. Adenot, Chemoporoplasticity of calcium leaching in concrete, J. Eng. Mech. 125 (1999) 1200-1211.

[37] D.N. Winslow, M.D. Cohen, D.P. Bentz, K.A. Snyder, E.J. Garboczi, Percolation and pore structure in mortars and concrete, Cem. Concr. Res. 24 (1994) 25-37.

[38] I. Yurtdas, S. Xie, J. Secq, N. Burlion, J. Shao, M. Sibai, P. Brossolet, B. Fraboulet, Couplage comportement mécanique et perméabilité: cas d'une pâte de ciment pétrolier dégradée chimiquement à $90^{\circ} \mathrm{C}$, Rev. Eur. Génie Civ. 11 (2007) $827-837$.

[39] J. Zheng C. Li, X. Zhou, Thickness of interfacial transition zone and cement content profiles around aggregates, Mag. Concr. Res. 57 (2005) 397-406.

[40] R. Zimbelmann, A contribution to the problem of cement-aggregate bond, Cem. Concr. Res. 15 (1985) 801-808. 